\title{
Clinical and immunological effects of vitamin D supplementation during the pollen season in children with allergic rhinitis
}

\author{
Joanna Jerzyńska ${ }^{1}$, Włodzimierz Stelmach², Błażej Rychlik ${ }^{3}$, Paweł Majak ${ }^{4}$, Daniela Podlecka ${ }^{1}$, \\ Katarzyna Woicka-Kolejwa' ${ }^{1}$, Iwona Stelmach ${ }^{1}$
}

\begin{abstract}
${ }^{1}$ Departament of Pediatrics and Allergy, Medical University of Lodz, N. Copernicus Hospital, Lodz, Poland

2Departament of Social and Preventive Medicine, Medical University of Lodz, Lodz, Poland

${ }^{3}$ Departament of Molecular Biophysics, University of Lodz, Lodz, Poland

${ }^{4}$ Departament of Internal Medicine, Asthma and Allergy, Medical University of Lodz, Lodz, Poland
\end{abstract}

Submitted: 28 April 2016

Accepted: 29 May 2016

Arch Med Sci 2018; 14, 1: 122-131

DOI: 10.5114 /aoms.2016.61978

Copyright @ 2016 Termedia \& Banach

\section{Abstract}

Introduction: Vitamin D deficiency has been proposed as a potential contributing factor in patients with allergic diseases. We compared the clinical and immunological effects of vitamin D supplementation to placebo during the pollen season in children with allergic rhinitis.

Material and methods: Thirty-eight children aged 5-12, sensitive to grass pollen, participated in a prospective, randomized, double-blind, placebo-controlled trial. Children received either vitamin D 1000 IU daily supplementation or placebo. We studied symptoms/medication score, lung function, exhaled nitric oxide concentration (FENO), methacholine bronchial provocation test and serum level of $25(\mathrm{OH}) \mathrm{D}$, as well as; CD4+CD25+Foxp3+ cells, TLR4, IL-1, IL-6, TNF and the IL-10 and transforming growth factor $\beta 1$ (TGF- $\beta 1$ ) levels in cell culture supernatants.

Results: Vitamin $D$ therapy was effective in reduction of the symptoms/ medication score $(p=0.0371)$. In vitamin $D$ group an increase in the CD4+CD25+Foxp3+ cells (7.06 vs. $10.5 \% ; p=0.0013)$ and serum $25(\mathrm{OH}) \mathrm{D}$ concentration ( 49.6 vs. $96.6 \mathrm{ng} / \mathrm{ml} ; p=0.0001$ ) and in control group an increase in FENO (15.6 vs. $21 \mathrm{ppb} ; p=0.0331$ ) and serum 25(OH)D level were observed ( 82.9 vs. $100.3 \mathrm{ng} / \mathrm{ml} ; p=0.0003)$. We revealed a higher increase from baseline in the percentage of CD4+CD25+Foxp3+ cells in the vitamin D group compared to the control group $(p=0.0058)$. A significant correlation between $C D 4+C D 25+F o x p 3+$ cell induction and FENO reduction in the vitamin D group was observed ( $p=0.0217)$.

Conclusions: Vitamin D 1000 IU as a supplementary treatment of grass pollen allergy in children with allergic rhinitis during the pollen season significantly reduced the symptoms/medication score. The study revealed an immunological effect of vitamin D.

Key words: vitamin D supplementation, children, allergic rhinitis.

\section{Introduction}

Allergic rhinitis (AR) is one of the most common allergic conditions, which affects the quality of life, academic achievement, and work performance.

\author{
Corresponding author: \\ Prof. Iwona Stelmach MD, \\ $\mathrm{PhD}$ \\ Department of Pediatrics \\ and Allergy \\ N. Copernicus Hospital \\ 62 Pabianicka St \\ 93-513 Lodz, Poland \\ Phone: +48426895972 \\ Fax: +48 426895973 \\ E-mail: alergol@ \\ kopernik.lodz.pl
}


The discovery that many cells express vitamin D receptors and the recognition of widespread vitamin D insufficiency have stimulated interest in the potential role of vitamin D in nonskeletal conditions, such as in the regulation of the function of both the innate and adaptive immune systems [1-4]. In recent years, the prevalence of allergic diseases has continued to rise, and vitamin D deficiency has been proposed as a potential contributing factor in patients with allergic diseases $[5,6]$. Data showed that there is a nonlinear association between $25(\mathrm{OH}) \mathrm{D}$ and $\mathrm{lgE}$, suggesting that there may be a threshold effect with both low and high 25(OH)D levels associated with elevated IgE concentrations [1]. A study indicated that increasing $25(\mathrm{OH}) \mathrm{D}$ serum concentrations are associated with decreased T-cell-dependent proinflammatory cytokine production [7]. Vitamin D has been shown to enhance interleukin (IL)-10 production by CD4+ T cells and enhance sublingual immunotherapy (SLIT) efficacy in a murine asthma model [8]. Recently, Heine et al. reported that 25-hydroxyvitamin $D_{3}$ promotes the long-term effect of specific immunotherapy in a murine allergy model paralleled by reduced Th2 cytokine expression in the lungs [9]. Their data show that both the sensitization and the desensitization by subcutaneous immunotherapy (SIT) are modulated by $25(\mathrm{OH}) \mathrm{D}$, leading to reduced humoral specific $\lg E$ and $\operatorname{lgG} 1$ induction and reduction of allergic airway inflammation following allergen airway exposure in vitamin D-deficient mice. The activation of the vitamin $D$ receptor on dendritic cells has been proven to modulate the tolerance of these antigen-presenting cells in adaptive immune responses [10,11]; an effect on the differentiation of naive T cells into Th2 cells has also been noted [12]. Boonstra et al. demonstrated that vitamin $\mathrm{D}$ inhibits interferon (IFN) $-\gamma$ production and promotes IL-10 production in a mouse model [12].

The aim of our study was to compare the clinical and immunological efficacy of vitamin D $1000 \mathrm{IU}$ daily supplementation during the pollen season (during high sun exposure in the summer) to placebo in children with allergic rhinitis, taking into account the fact of vitamin D deficits in Central Europe in the general population [13]. Vitamin D or placebo was given pre-coseasonally (starting at least 8 weeks before the pollen season and continuing until the end of it) in children allergic to grass pollen.

\section{Material and methods}

\section{Subjects}

We included 50 children, aged 5-12, living in the same geographical location, sensitive only to grass pollen, with a clinical diagnosis of grassrelated moderate-to-severe rhinoconjunctivitis (according to Allergic Rhinitis and its Impact on Asthma 2014 recommendation) [14] with a dura- tion of at least 1 year before the first study visit; 6 patients had concomitant asthma (intermittent or mild-to-moderate persistent, according to Global Initiative for Asthma 2014 criteria) [15]. All subjects with an asthma diagnosis were treated by their doctors according to GINA guidelines for a minimum of 6 months and their asthma was well controlled. Subjects allergic to perennial allergens, or with severe or unstable asthma, were excluded from the study. Exclusion criteria also included active upper respiratory tract infection within 1 month before the first study visit, and any previous or present immunotherapy or clinically significant pulmonary, hematologic, hepatic, gastrointestinal, renal, endocrine, neuronal, cardiovascular and/or psychiatric diseases or malignancies, which could either put them at risk during their participation in the study or might have influenced the results of the study (as judged by the investigator). Finally, excluded medications were systemic corticosteroids or immune suppressive drugs, as well as supplementary vitamin D (or any vitamin supplements) used within 6 months before the study.

The study was approved by the Medical Ethics Committee of the Medical University of Lodz. All parents or guardians of the patients gave their oral and written consent for the evaluation of data from medical documentation of their children.

\section{Study design}

We performed a 5-month (between March 2014 and July 2014) prospective, randomized, double-blind, placebo-controlled study of children to compare the efficacy of pre-coseasonal vitamin D 1000 IU daily or placebo supplementation in children allergic to grass pollen. All suitable subjects were randomized according to a computer-generated allocation schedule into the two treatment arms: the vitamin D group with vitamin D 1000 IU daily supplementation $(n=25)$, and the control (placebo) group with vitamin D placebo supplementation $(n=25)$. All subjects were recruited from our specialty clinic setting.

The primary endpoints included clinical efficacy based on the reduction in symptoms/medication score as well as lung function, exhaled nitric oxide concentration (FENO), methacholine bronchial provocation test and serum level of 25(OH)D. We also aimed to determine whether improvement in lung function after clinical effectiveness of vitamin D 1000 IU supplementation, if any, depends on the serum level of $25(\mathrm{OH}) \mathrm{D}$ in children. The safety was estimated on the basis of adverse symptoms. The secondary endpoint of the study was the immunological efficacy. The immunological parameters included measurements of the following: a) surface molecules (CD4+CD25+Foxp3+ cells, 
TLR4), IL-1, IL-6, TNF - direct evidence of TLR activation; and $b$ ) the IL-10 and transforming growth factor $\beta 1$ (TGF- $\beta 1$ ) levels in cell culture supernatants.

The clinical and immunological efficacy was evaluated for 5 months during the pollen season. The patients attended one pre-study and two study visits at the clinic. During the pre-study visit, before March 2014, all participants were informed about the purpose of the study, were told how to score asthma/allergic symptoms and underwent skin testing. Patients were classified as atopic based on history and positive skin prick testing for common allergens. In patients unable to undergo skin testing, a serum-specific IgE for a specific allergen was employed. During the pre-study visit, a diet with similar vitamin D intake was recommended for all patients. All children remained in the same geographical area during the study, so that they all were under the same sunlight exposure. During the first study visit (first week of March, 2014) patients received vitamin $D$ supplementation or placebo. The second visit took place five months after the first visit, at the end of the grass pollen season. During each study visit, blood samples were obtained from all patients to assess immunological parameters as well as vitamin D serum level. Lung function and exhaled nitric oxide concentration were measured, the methacholine bronchial provocation test was performed, and the patients' diaries were also evaluated. Both study visits were scheduled in such a way that blood sampling in individual patients always took place at the same time and on the same day of each week.

\section{Treatment}

Both groups were treated once daily with either vitamin D containing $1000 \mathrm{IU}$ ( $25 \mu \mathrm{g}$ of cholecalciferol, Vigantoletten 1000, Merck KGaA) or identically looking placebo. Vitamin D and placebo were blinded (prepared in wafers with $0.3 \mathrm{mg}$ of lactose) by the hospital pharmacy. Every morning at home, before breakfast all patients received a wafer with vitamin D or placebo. Each wafer was placed in the empty mouth and then swallowed. Children were treated at least 8 weeks before the grass pollen season and through the entire season, for a total of at least 20 weeks after randomization. Since we administered high doses of vitamin D (1000 IU daily) according to the latest guidelines for Central Europe, we measured calcium-phosphorus metabolism in blood in individual patients [13].

To assess adherence to the treatment all subjects were asked to bring all empty packages to the last visit. The onset of the pollen season was defined as the first of 3 consecutive days with grass pollen counts of at least 10 grains $/ \mathrm{m}^{3}$ and its end as the last day before 3 consecutive days with a grass pollen count of less than 10 grains $/ \mathrm{m}^{3}$.
A pollen count was performed throughout the study for the region of interest [16]. During the pollen season, all children received at baseline the standard treatment of allergic rhinoconjunctivitis - systemic antihistamines. Other permissible treatments included nasal steroids, local antihistamines or cromones for eyes, inhaled corticosteroids (ICS) in minimal doses necessary to control the symptoms, a short-acting $\beta_{2}$-agonist for quick relief, and standard treatments of the infections and exacerbations of asthma.

\section{Efficacy assessment. Symptom-medication score}

The combined symptom-medication score (SMS) was calculated as the sum of the symptom score (SS) and the medication score (MS) recorded by the patients on a daily basis during the season from March to July. SS was recorded using a point score system for the most common symptoms of rhinitis (rhinorrhea, sneezing, itching, and nasal congestion), conjunctivitis (ocular pruritus, watery eyes, itching), and respiratory disorders (cough, wheeze, and dyspnea). A score ranging from 0 to 3 was used for each symptom: 0 - no symptoms; 1 - mild symptoms (symptoms clearly present but easily tolerated); 2 - moderate symptoms (definite awareness of bothersome but tolerable symptoms); 3 - severe symptoms (symptoms hard to tolerate and causing interference with daily activities and/or sleeping). The minimum score for each day was 0 (no symptoms during the day, no symptoms at night), and the maximum score was 30 (severe symptoms during the day and at night). Additionally, every use of medication was registered (1 point for each allowed medication multiplied by the number of treatment days) [17].

\section{Lung function test}

Pulmonary function testing was performed with a Master Screen unit (Erich Jaeger $\mathrm{GmbH}$ Hochberg, Germany). Predicted values for all lung function variables were based on a previous study of healthy controls, provided by the manufacturer of the lung function test equipment [18]. Flow-volume curves were performed according to American Thoracic Society standards [18]. The highest of 3 successful measurements was taken. The results were expressed as the percentage of a predicted value. We evaluated the following lung function parameters: forced expiratory volume in $1 \mathrm{~s}\left(\mathrm{FEV}_{1}\right)$, and forced expiratory volume in $1 \mathrm{~s} \%$ vital capacity ( $\mathrm{FEV} \% \mathrm{VC})$, also called the Tiffeneau-Pinelli index (the proportion of a person's vital capacity that they are able to expire in the first second of forced expiration). 


\section{Nitric oxide (NO) measurement}

The NO measurements were performed according to ERS/ATS recommendations [19] with a chemiluminescence analyzer (model 280i nitric oxide analyzer; Sievers, Boulder, CO, USA) and defined in parts per billion. The analyzer provides an on-line continuous measurement of $\mathrm{NO}$ in a single exhalation with a detection range of 0.1 to $500 \mathrm{ppb}$. Environmental NO was measured before and after each test and never exceeded $5 \mathrm{ppb}$. All subjects were studied in the sitting position, without wearing a nose clip. The subjects exhaled at a constant flow rate $(50 \mathrm{ml} / \mathrm{s})$ from total lung capacity to residual volume without breath holding. They maintained a constant mouth pressure (17 $\mathrm{cm} \mathrm{H}_{2} \mathrm{O}$ ) by monitoring a visual display in order to eliminate contamination from nasal NO. Dead space and nasal NO (which are reflected by the NO concentration peak during exhalation) and NO from the lower respiratory tract (determined by the plateau value after the peak) were recorded automatically using the manufacturer's software. Three FENO measurements of the plateau phase were obtained, with less than $10 \%$ variation. The mean value of 3 successive, reproducible recordings was retained for statistical analysis.

\section{Methacholine bronchial provocation test (MBPT)}

A methacholine bronchial provocation test was performed at the beginning and at the end of the study, before and after immunotherapy (March and July 2014), using the dosimeter APS Pro (Erich Jaeger GmbH, Hochberg, Germany) with controlled tidal breathing. After pulverization of the physiological diluent, methacholine was delivered in four cumulative doses: 0.015 $\mathrm{mg}, 0.045 \mathrm{mg}, 0.18 \mathrm{mg}, 0.72 \mathrm{mg}$. Methacholine bronchial provocation test was continued with 2-min intervals between the inhalations until a fall in $\mathrm{FEV}_{1}$ of $\geq 20 \%$ was obtained. The dose of metacholine provoking a $20 \%$ fall in $\mathrm{FEV}_{1}$ from the prechallenge value (provocative dose 20 PD20) was calculated by linear interpolation on a log-dose response curve.

\section{Vitamin D measurement}

Serum 25(OH)D was measured by radioimmunoassay (Biosource, Camarillo, CA, USA) according to the manufacturer's instructions. Calcium and phosphorus were measured by standard methods.

\section{Assessment of the immunologic effects of vitamin D supplementation}

One sample of peripheral blood mononuclear cells (PBMCs) was isolated from whole blood by density gradient centrifugation on Histopaque-1077 (Sigma-Aldrich, Highland, Illinois, USA). Surface expression of TLR4 (eBioscience, San Diego, California, USA) was determined using a flow cytometer (Becton Dickinson) and analyzed using CellQuest software (Becton Dickinson). CD14+ cells were used for the analysis of TLR.

Other sample of peripheral blood mononuclear cells (PBMCs) was isolated from whole blood by density gradient centrifugation on Histopaque-1077 (Sigma-Aldrich, Highland, Illinois, USA) and cultured in standard mammalian cell culture conditions $\left(37^{\circ} \mathrm{C}, 5 \%\right.$ carbon dioxide, $80 \%$ relative humidity) in the presence of grass allergen. Surface molecule CD4+CD25+Foxp3+ expression on cultured PBMCs was estimated by flow cytometry (LSRII instrument; BD Biosciences, San Jose, California) using appropriate fluorophore-conjugated monoclonal antibodies. The IL-1, IL-6, IL-10, TGF- $\beta 1$, and TNF- $\alpha$ levels in cell culture supernatants were determined using enzyme-linked immunosorbent assay-based specific tests (R\&D, Minneapolis, Minnesota) according to the manufacturer's instructions.

\section{Safety}

During each visit, an interview and a physical examination were performed. All adverse events were recorded.

\section{Statistical analysis}

First, within-group comparisons using the Wilcoxon test were implemented. Second, beforeafter changes in each variable were compared between groups using the Mann-Whitney test. Spearman correlation analysis was used to assess associations between clinical and laboratory end-points. All of the statistical analyses were performed using Statistica for Windows ver. 8.0. The null hypothesis was rejected if $p<0.05$.

\section{Results}

\section{Subjects}

Thirty-eight patients completed the study. From amongst them, 21 study participants were assigned to a group receiving vitamin D 1000 IU daily doses, while 17 children were allocated to a group receiving vitamin D placebo; 4 patients from the vitamin $D$ group and 8 patients from the placebo group were excluded due to poor adherence. Baseline characteristics are shown in Table I. All clinical measures were comparable between study groups. The symptoms/medication score was calculated once at the end of the pollen season and was significantly lower in children from the vitamin $D$ group compared to patients from the control group; $p=0.0371$ (Figure 1). The occurrence of asthma (comorbidity) was of no statistical 
Table I. Baseline characteristics. Data presented as median (interquartile range)

\begin{tabular}{|lccc|}
\hline Parameter & $\begin{array}{c}\text { Vitamin D group } \\
(n=21)\end{array}$ & $\begin{array}{c}\text { Control group } \\
(n=17)\end{array}$ & $P$-value \\
\hline FEV $_{1}$ (\%pred.) & $104(96-108)$ & $101(97-112)$ & 0.8391 \\
\hline FEV $\%$ FVC (\% pred.) & $101(96-109)$ & $101(98-103)$ & 0.7717 \\
\hline FENO [ppb] & $21.6(11.0-45.4)$ & $15.6(9.2-21.8)$ & 0.2317 \\
\hline Vitamin D serum level $[\mathrm{ng} / \mathrm{ml}]$ & $49.6(36.9-78.6)$ & $82.9(36.7-87.1)$ & 0.1989 \\
\hline
\end{tabular}

A
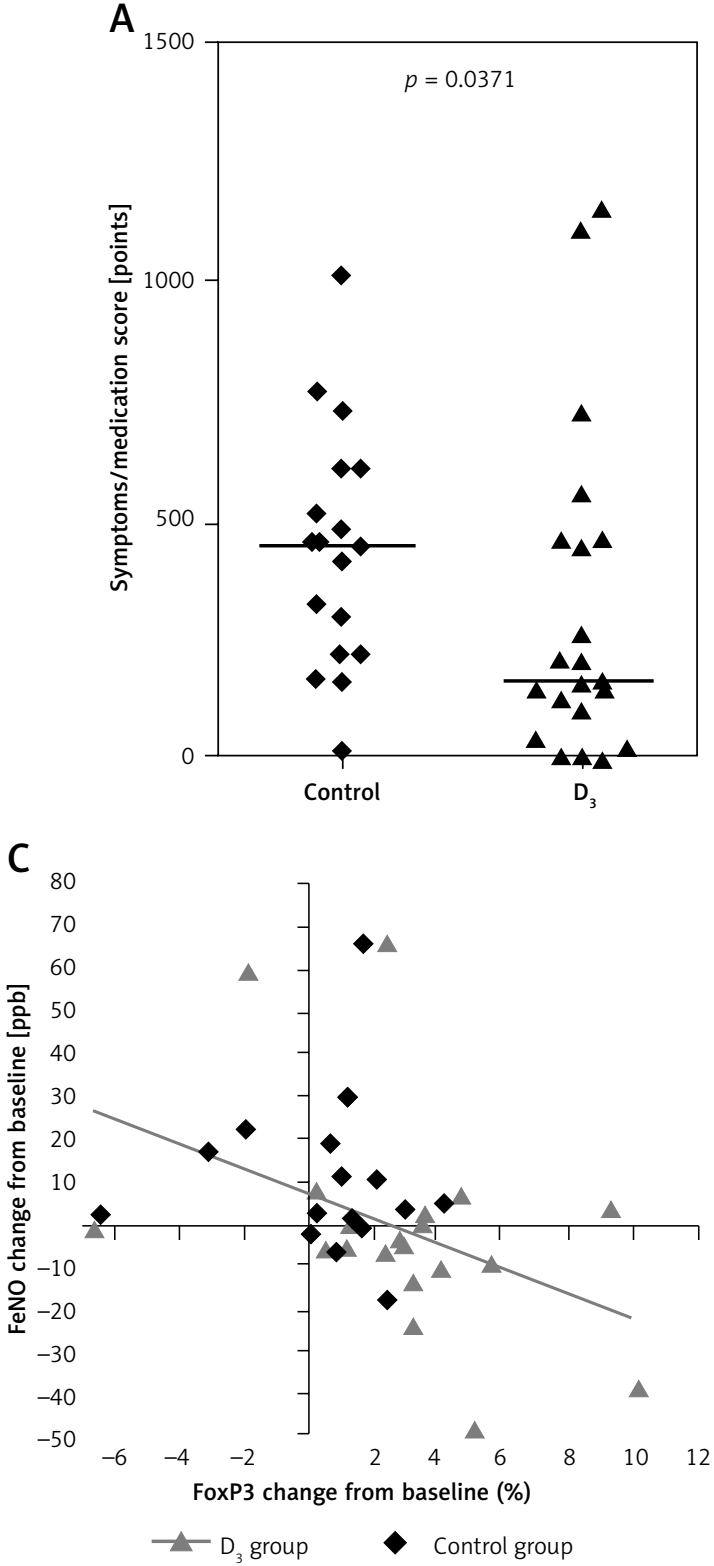

significance either. There were no differences in dose of allergy medications between the groups.

\section{Grass pollen season}

The 2014 grass pollen season for the region of interest had a mean pollen count of approximately 53 grains $/ \mathrm{m}^{3}$ over the entire season, which lasted

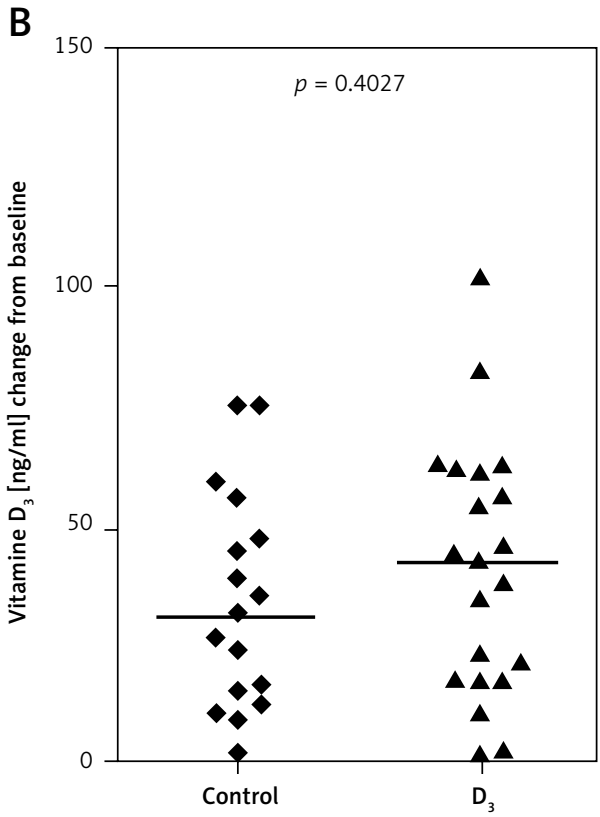

Figure 1. Changes in clinical parameters in children from the vitamin D group compared to children from the control group; between-group analysis. Relative changes in serum concentration of $25(\mathrm{OH}) \mathrm{D}$ between visit \#1 and visit \#2 in both study groups. The correlation between CD4+CD25+Foxp3+ cell induction and FENO reduction

77 days. The season was characterized by a few pollen peaks, with an average peak season count of 144 grains $/ \mathrm{m}^{3}$.

\section{Within-group comparisons}

In children from the vitamin $D$ group significantly increase percentage of CD4+CD25+Foxp3+ cells 
and serum 25(OH)D concentration were observed, whereas in children from the control group increases in FENO and serum 25(OH)D level were observed (Figures 1 and 2, Table II). Changes in other measures did not reach the level of significance (Table II).

We observed a significant decrease in phosphorus serum levels in the vitamin $\mathrm{D}$ group $(p=$ 0.012 ) and a significant increase in phosphorus in the placebo group $(p=0.02)$.

\section{Between-group comparisons}

We observed a significant difference between groups in the induction of CD4+CD25+Foxp3+ cells during the pollen season; the increase from baseline in percentage of CD4+CD25+Foxp3+ was significantly higher in the vitamin $D$ group compared to the control group (Figure 2).

\section{Correlation analysis}

We observed a significant correlation between CD4+CD25+Foxp3+ cell induction and FENO reduction (Table III). This correlation was observed in the vitamin D group only (Figure 1).

\section{Safety results}

Vitamin D was well tolerated in the patients. All subjects brought empty packages of drugs to the last visit according to the study design.

\section{Discussion}

Recently, there has been increased worldwide interest in the association between vitamin $D$ deficiency and occurrence of allergic disease, but the studies have shown inconsistent results. Jung et al. reported a potential relation between vitamin $D$ deficiency and AR prevalence in Korean adults [20]. A study performed in 2012 reported that vitamin $D$ deficiency occurs more often in AR patients than in the normal population [21]. In contrast, some studies reported that a high vitamin D level is a risk factor for occurrence of allergic diseases [22], while others proposed that both high and low 25-hydroxyvitamin D levels were associated with morbidity and mortality of the disease $[23,24]$.

Vitamin $D$ has been reported to increase serum levels of the immunomodulatory cytokines TGF- $\beta$ and IL-10 in humans [25] and to enhance the benefits of allergen immunotherapy in a murine model by IL-10 and TGF- $\beta$ dependent mechanisms [26]. In human subjects CD4+CD25+Foxp3+ (Treg) cells appear to play a major role in inhibiting allergic disorders [27]. Vitamin D has been shown to promote tolerogenic dendritic cells, leading to the induction of Foxp3+ regulatory cells [28]. In our previous study, we observed the effect of vitamin D combined with SLIT on the early immunological response measured by CD4+CD25+Foxp3+
A

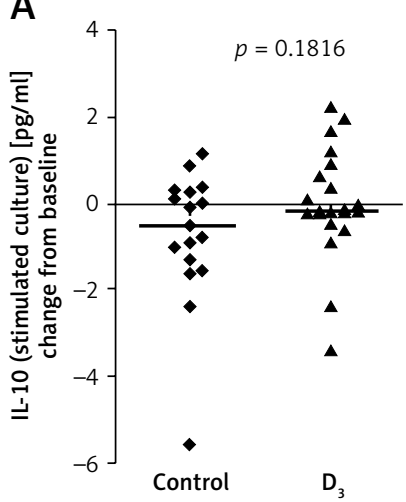

D

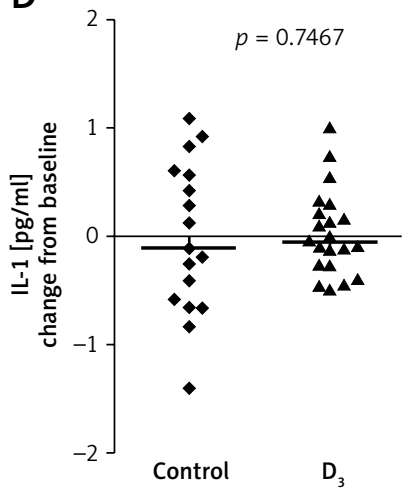

B

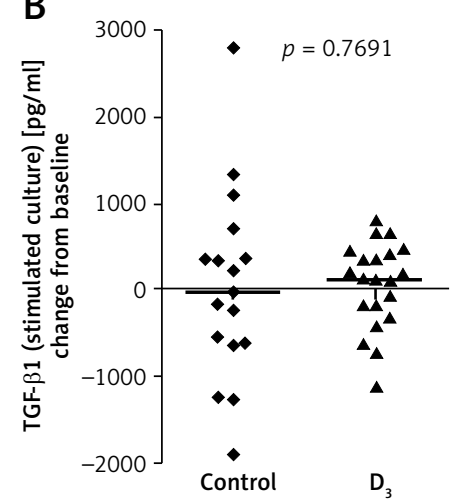

E

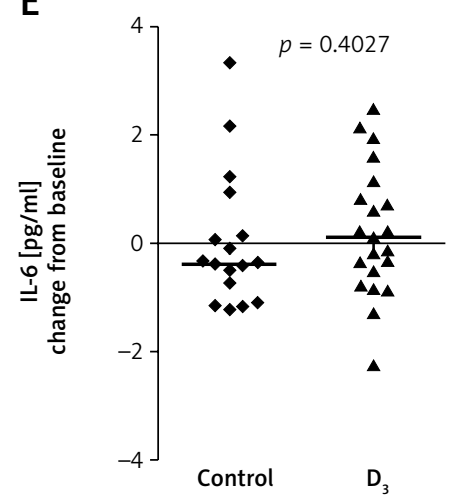

C

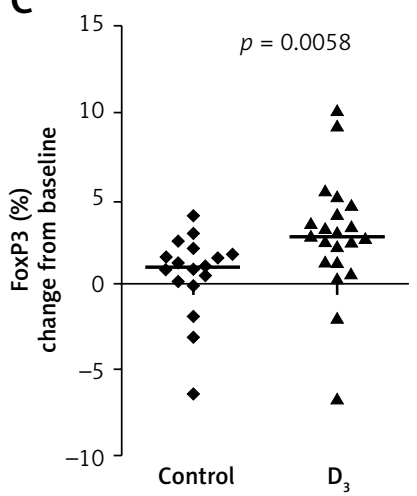

F

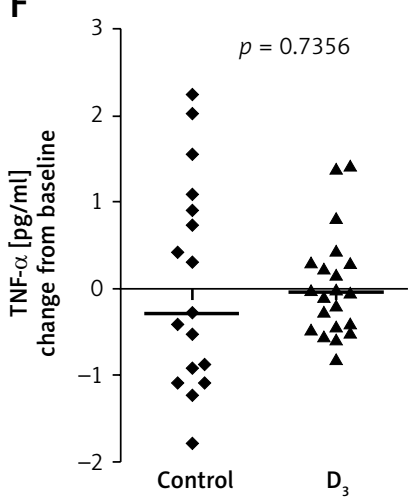

Figure 2. Changes in immunological parameters in children from the vitamin D group compared to children from the control group; between-group analysis 
Joanna Jerzyńska, Włodzimierz Stelmach, Błażej Rychlik, Paweł Majak, Daniela Podlecka, Katarzyna Woicka-Kolejwa, Iwona Stelmach

Table II. Before-after comparisons of study end-points. Data presented as median (interquartile range)

\begin{tabular}{|c|c|c|c|}
\hline Parameter & Before & After & $P$-value \\
\hline \multicolumn{4}{|l|}{ Vitamin D group $(n=21)$ : } \\
\hline IL-10 [pg/ml] & $0.38(0.14-0.68)$ & $0.49(0.2-1.02)$ & 0.9256 \\
\hline TGF- $\beta[\mathrm{pg} / \mathrm{ml}]$ & $843(397-1092)$ & $972(462-1135)$ & 0.5430 \\
\hline CD4+CD25+Foxp3+ (\%) & $7.06(5.5-8.47)$ & $10.5(7.99-12.1)$ & 0.0013 \\
\hline IL-1 [pg/ml] & $0.39(0.23-0.53)$ & $0.18(0.11-0.63)$ & 0.8373 \\
\hline TNF- $\alpha[p g / m l]$ & $0.59(0.41-0.94)$ & $0.66(0.25-1.11)$ & 0.7651 \\
\hline IL-6 [pg/ml] & $0.95(0.51-1.28)$ & $1.27(0.87-1.32)$ & 0.5781 \\
\hline $\mathrm{FEV}_{1}$ (\%pred.) & $103.6(96.2-108.3)$ & $107.4(99-114.2)$ & 0.0537 \\
\hline $\mathrm{FEV}_{1} \% \mathrm{FVC}$ (\%pred.) & $100.5(96.1-109)$ & $103.1(100.5-110.5)$ & 0.1098 \\
\hline FENO [ppb] & $21.6(11-45.4)$ & $20.1(16.3-29.5)$ & 0.2959 \\
\hline Vitamin D [ng/ml] & $49.6(36.9-78.6)$ & $96.6(82.6-102.3)$ & 0.0001 \\
\hline \multicolumn{4}{|l|}{ Control group $(n=17)$ : } \\
\hline IL-10 [pg/ml] & $1.08(0.36-2.08)$ & $0.58(0.25-1.02)$ & 0.0929 \\
\hline TGF- $\beta[\mathrm{pg} / \mathrm{ml}]$ & $804(310-1454)$ & 1017 (461-1314) & 0.9811 \\
\hline CD4+CD25+Foxp3+ (\%) & $7.99(6.67-9.47)$ & $8.6(6.86-10.1)$ & 0.1359 \\
\hline IL-1 [pg/ml] & $0.57(0.4-0.71)$ & $0.46(0.03-1.04)$ & 0.9434 \\
\hline TNF- $\alpha[p g / m l]$ & $1.02(0.51-1.18)$ & $0.54(0.12-1.41)$ & 0.8684 \\
\hline IL-6 [pg/ml] & $1.09(0.58-1.23)$ & $0.975(0-1.72)$ & 0.5695 \\
\hline $\mathrm{FEV}_{1}$ (\%pred.) & $101(96.8-112.1)$ & $101.2(96.4-111.1)$ & 0.6051 \\
\hline $\mathrm{FEV}_{1} \% \mathrm{FVC}$ (\%pred.) & $100.5(98.1-102.6)$ & $99.7(96.3-104.5)$ & 0.5177 \\
\hline FENO [ppb] & $15.6(9.2-21.8)$ & $21(15.2-30)$ & 0.0331 \\
\hline Vitamin D [ng/ml] & $82.9(36.7-87.1)$ & $100.3(97.4-120.3)$ & 0.0003 \\
\hline
\end{tabular}

Table III. Correlations between clinical and laboratory parameters. All participants are included $(n=38)$

\begin{tabular}{|c|c|c|c|c|c|}
\hline \multirow[t]{2}{*}{ Parameter } & & \multirow{2}{*}{$\begin{array}{l}\text { Symptoms/medication } \\
\text { score during the season } \\
\text { [points] }\end{array}$} & \multicolumn{3}{|c|}{ Change from baseline } \\
\hline & & & $\mathrm{FEV}_{1}(\%)$ & $\mathrm{FEV}_{1} \% \mathrm{FVC}(\%)$ & FENO [ppb] \\
\hline \multicolumn{6}{|l|}{ Baseline value: } \\
\hline \multirow[t]{2}{*}{ IL-10 [pg/ml] } & $R$ & -0.08 & -0.07 & 0.07 & -0.13 \\
\hline & $p$ & 0.6283 & 0.6929 & 0.6823 & 0.4279 \\
\hline \multirow[t]{2}{*}{ TGF- $\beta[\mathrm{pg} / \mathrm{ml}]$} & $R$ & 0.09 & 0.09 & 0.07 & 0.09 \\
\hline & $p$ & 0.6002 & 0.5827 & 0.6905 & 0.5723 \\
\hline \multirow[t]{2}{*}{ CD4+CD25+Foxp3+[\%] } & $R$ & 0.15 & 0.00 & 0.00 & -0.10 \\
\hline & $p$ & 0.3573 & 0.9943 & 0.9938 & 0.5546 \\
\hline \multirow[t]{2}{*}{ Vitamin D [ng/ml] } & $R$ & 0.13 & -0.11 & 0.06 & -0.12 \\
\hline & $p$ & 0.4369 & 0.5177 & 0.7013 & 0.4619 \\
\hline \multicolumn{6}{|l|}{ Change from baseline: } \\
\hline \multirow[t]{2}{*}{ CD4+CD25+Foxp3+[\%] } & $R$ & -0.23 & -0.09 & 0.02 & -0.37 \\
\hline & $p$ & 0.1663 & 0.5768 & 0.8836 & 0.0217 \\
\hline \multirow[t]{2}{*}{ Vitamin D [ng/ml] } & $R$ & -0.18 & 0.06 & -0.13 & -0.06 \\
\hline & $p$ & 0.2787 & 0.7255 & 0.4465 & 0.7086 \\
\hline
\end{tabular}

$R$-Spearman correlation coefficient, $p-p$-value. 
induction in patients after 5 months of SLIT [29]. The present study demonstrates a clinical and immunological effect of vitamin D 1000 IU daily supplementation in children with allergic rhinitis. A significant reduction in symptoms/medication score in children receiving vitamin D 1000 IU daily supplementation was observed compared to those receiving placebo. A significantly higher increase from baseline in percentage of CD4+CD25+ Foxp3+ cells during the pollen season in the vitamin $D$ group compared to the placebo group was observed. We also found a significant correlation between $\mathrm{CD} 4+\mathrm{CD} 25+$ Foxp3+ cell induction and FENO reduction in the vitamin $D$ group. Before-after changes in vitamin D levels are also probably due to sun exposure during the follow-up, since the levels are similar between the vitamin D group and the control group. However, both groups reminded under the same sunlight exposure, so we can assume that the observed differences in clinical and immunological outcomes are attributable to vitamin D supplementation.

It has been demonstrated that lower levels of vitamin D are associated with reduced asthma control [30]. In our study, improvement in symptoms observed during vitamin D supplementation was not correlated with the serum level of vitamin D. Our study is in agreement with other studies, that it is still not confirmed that a U-shaped relationship exists between overdose and under-dose of vitamin D. Although vitamin D supplementation shows immunological effects, it does not always show a clinical effect.

Due to ethical reasons methacholine challenge was performed outside the pollen season. Nevertheless, we recognized the assessment of bronchial hyperresponsiveness just before and after the pollen season as a valuable study endpoint. Nitric oxide is an important inflammatory mediator of biological functions in the airways [31], and exhaled nitric oxide is a useful marker determining the degree of bronchial hyperreactivity [32], e.g. the levels of FENO in air exhaled by asthmatic patients are elevated [33]. We did not observe any improvement of the morning $\mathrm{FEV}_{1}$ and $\mathrm{FEV}_{1} \% \mathrm{VC}$ levels or PD20 within the treatment groups; FENO level increased significantly within the placebo group. However, our results regarding lung function parameters are not very clear due to the small numbers of asthmatic patients distributed across both groups.

We were able to demonstrate a correlation between CD4+CD25+Foxp3+ cell induction and FENO reduction. This correlation was observed in the vitamin D group only, but one could conclude that this effect occurred by chance. However, we have previously shown that the serum level of 25(OH)D above $30 \mathrm{ng} / \mathrm{ml}$ facilitates the optimal effect of allergen immunotherapy [27]. Therefore it is fair to say that vitamin D modulates the allergic response.

The active form of vitamin D modulates helper T-cell action by suppressing Th1 cytokine secretion. There are a few studies which demonstrate that vitamin $D$ leads to an increase in interleukin (IL)-10 expression and a decrease in IL-2 expression [34, 35]. Also, vitamin D decreases IL-12 production; thus it can reduce the differentiation of Th1 cells and increase the differentiation Th2 cells, which are responsible for allergic reactions [36]. In the present study there was no significant difference in the level of measured cytokines.

In our study, administration of 1000 IU vitamin D once daily significantly reduced phosphorus in serum of children, which suggests its safety with respect to calcium-phosphorus metabolism and collagen turnover in children. The clinical implication of our study suggesting that the supplementation of vitamin D should be recommended for treatment of allergic rhinitis in children is justified by its safety.

The main limitation of the study is the relatively small sample size with a low number of patients with asthma. However, the sample size was determined on the basis of the recommendations to reach the necessary power [37]. Also, at baseline the symptoms/medication score is higher in the control group than in the vitamin D group; vitamin D levels are higher in the control group compared to the intervention group. However, the observed between-groups difference in baseline level of vitamin D did not reach the level of significance. Such a discrepancy is the result of randomization without any stratification. Study end-points were compared between groups as relative changes, which in our opinion overcomes the above problem. Available literature suggests that not baseline but rather relative change in vitamin D serum level may determine the clinical effects of its supplementation. The methods used in our study - only 1 year of observation - are not suitable to report the cause and effect relation. In order to assess this relation, both the control and vitamin D groups should be prospectively followed. Therefore, our results should be verified in a well-designed, randomized control trial.

Our results provide direct evidence for the effectiveness and safety of vitamin D 1000 IU as a supplementary treatment of grass pollen allergy in children with allergic rhinitis during the pollen season. However, how such a complex system may translate into supplementation advice for the general population is yet to be understood. It cannot be excluded that the effects associated with supplementation of vitamin D are due to genetic, individual or environmental factors which have not been examined yet. Therefore, it may be difficult to identify the causal relationship between 
vitamin D level and development of disease. Additional studies, with adequate sample size, dose adjustment based on target serum vitamin D levels, longer duration of treatment, and adequate correction for confounding factors such as sun/ UVB exposure and food intake, are currently much needed.

\section{Acknowledgments}

The pollen count was provided by Prof. M.L. Kowalski and B. Wojciechowska of the Department of Immunology, Rheumatology and Allergy, Medical University of Lodz, Poland.

\section{Conflict of interest}

The authors declare no conflict of interest.

\section{References}

1. Hypponen E, Berry DJ, Wjst M, Power C. Serum 25-hydroxyvitamin D and IgE - a significant but nonlinear relationship. Allergy 2009; 64: 613-20.

2. Ambroszkiewicz J, Rowicka G, Chelchowska M, Gajewska J, Strucińska M, Laskowska-Klita T. Biochemical markers of bone metabolism in children with cow's milk allergy. Arch Med Sci 2014; 10: 1135-41.

3. Krela-Kaźmierczak I, Szymczak A, Łykowska-Szuber L, et al. The importance of vitamin $D$ in the pathology of bone metabolism in inflammatory bowel diseases. Arch Med Sci 2015; 11: 1028-32.

4. Szekely JI, Pataki A. Effects of vitamin D on immune disorders with special regard to asthma, COPD and autoimmune diseases: a short review. Exp Rev Respir Med 2012; 6: 683-704.

5. Yenigun A, Dadaci Z, Oncel M. Plasma vitamin D levels of patients with allergic rhino-conjunctivitis with positive skin prick test. Am J Rhinol Allergy 2015; 29: e46-9.

6. Kim YH, Kim KW, Kim MJ, et al. Vitamin D levels in allergic rhinitis: a systematic review and meta-analysis. Pediatr Allergy Immunol 2016 May 18. doi: 10.1111/ pai.12599.

7. Drozdenko G, Heine G, Worm M. Oral vitamin D increases the frequencies of CD38+ human $B$ cells and ameliorates IL-17-producing T cells. Exp Dermatol 2014; 23: 107-12.

8. Van Overvelt L, Van Overtvelt L, Lombardi V, et al. IL-10-inducing adjuvants enhance sublingual immunotherapy efficacy in a murine asthma model. Int Arch Allergy Immunol 2008; 145: 152-62.

9. Heine G, Tabeling C, Hartmann B, et al. 25-hydroxvitamin D3 promotes the long-term effect of specific immunotherapy in a murine allergy model. J Immunol 2014; 193: 1017-23.

10. Adorini L, Penna G, Giarratana N, Uskokovic M. Tolerogenic dendritic cells induced by vitamin $\mathrm{D}$ receptor $\mathrm{li}$ gands enhance regulatory $T$ cells inhibiting allograft rejection and autoimmune diseases. J Cell Biochem 2003; 88: 227-33.

11. Wintergerst ES, Maggini S, Hornig DH. Contribution of selected vitamins and trace elements to immune function. Ann Nutr Metab 2007; 51: 301-23.

12. Boonstra A, Barrat FJ, Crain C, Heath VL, Savelkoul HFJ, O'Garra A. 1alpha,25-dihydroxyvitamin D3 has a direct effect on naive CD4 T cells to enhance the development of Th2 cells. J Immun 2001; 167: 4974-80.

13. Płudowski P, Karczmarewicz E, Bayer M, et al Practical guidelines for the supplementation of vitamin $D$ and the treatment of deficits in Central Europe - recommended vitamin $D$ intakes in the general population and groups at risk of vitamin D deficiency. Endokrynol Pol 2013; 64: 319-27.

14. Bousquet J, Khaltaev N, Cruz AA, et al. Allergic Rhinitis and its Impact on Asthma (ARIA) 2008 Update (in collaboration with the World Health Organization, GA2LEN*and AllerGen**). Allergy 2008; 63 Suppl.: 8-160.

15. Global Initiative for Asthma (GINA). Global strategy for asthma management and prevention. http://www.ginasthma.org/documents/4. Accessed 2013.

16. Available at: http://immunologia.umed.pl/p/u-nas/monitor-pylkowy

17. Wasserfallen JB, Gold K, Schulman KA, Baraniuk JN. Development and validation of a rhinoconjunctivitis and asthma symptom score for use as an outcome measure in clinical trials. J Allergy Clin Immunol 1997; 100: 16-22.

18. Miller MR, Hankinson J, Brusasco V, et al. ATS/ERS TaskForce. Standardisation of spirometry. Eur Respir J 2005; 26: 319-38.

19. Recommendations for standardized procedures for the on-line and off-line measurement of exhaled lower respiratory nitric oxide and nasal nitric oxide in adults and children-1999. This official statement of the American Thoracic Society was adopted by the ATS Board of Directors, July 1999. Am J Respir Crit Care Med 1999; 160: 2104-17.

20. Jung JW, Kim JY, Cho SH, Choi BW, Min KU, Kang HR. Allergic rhinitis and serum 25-hydroxyvitamin $D$ level in Korean adults. Ann Allergy Asthma Immunol 2013; 111: 352-7.

21. Arshi S, Ghalehbaghi B, Kamrava SK, Aminlou M. Vitamin $D$ serum levels in allergic rhinitis: any difference from normal population? Asia Pac Allergy 2012; 2: 45-8.

22. Back O, Blomquist HK, Hernell O, Stenberg B. Does vitamin D intake during infancy promote the development of atopic allergy? Acta Derm Venereol 2009; 89: 28-32.

23. Melamed ML, Michos ED, Post W, Astor B. 25-hydroxyvitamin $D$ levels and the risk of mortality in the general population. Arch Intern Med 2008; 168: 1629-37.

24. Heaney RP. Vitamin D: how much do we need, and how much is too much? Osteoporos Int 2000; 11: 553-5.

25. Urry Z, Xystrakis E, Richards DF, et al. Ligation of TLR9 induced on human IL-10-secreting Tregs by 1alpha,25-dihydroxyvitamin D3 abrogates regulatory function. J Clin Invest 2009; 119: 387-98.

26. Taher YA, van Esch BC, Hofman GA, et al. 1alpha,25-dihydroxyvitamin D3 potentiates the beneficial effects of allergen immunotherapy in a mouse model of allergic asthma: role for IL-10 and TGF-beta. J Immunol 2008; 180: 5211-21.

27. Majak P, Jerzyńska J, Smejda K, Stelmach I, Timler D, Stelmach W. Correlation of vitamin D with Foxp3 induction and steroid-sparing effect of immunotherapy in asthmatic children. Ann Allergy Asthma Immunol 2012; 109: 329-35.

28. Penna G, Roncari A, Amuchastegui S, et al. Expression of the inhibitory receptor ILT3 on dendritic cells is dispensable for induction of CD4+Foxp3+ regulatory T cells by 1,25-dihydroxyvitamin D3. Blood 2005; 106: 3490-7.

29. Jerzynska J, Stelmach W, Balcerak J, et al. Effect of Lactobacillus rhamnosus $\mathrm{GG}$ and vitamin $\mathrm{D}$ supplementation on the immunological effectiveness of grass-specific 
SLIT in allergic children. Allergy Asthma Proc 2016; 37: 324-34.

30. Lange NE, Litonjua A, Hawrylowicz CM, Weiss S. Vitamin D, the immune system and asthma. Exp Rev Clin Immunol 2009; 5: 693-702.

31. Nathan C, Xie QW. Regulation of biosynthesis of nitric oxide. J Biol Chem 1994; 269: 13725-8.

32. Attanasi M, Consilvio NP, Rapino D, et al. Bronchial hyperresponsiveness to mannitol, airway inflammation and Asthma Control Test in atopic asthmatic children. Arch Med Sci 2016; 12: 137-44.

33. Kim SH, Yoon HJ. Use of the exhaled nitric oxide for management of asthma and respiratory diseases. Korean J Med 2008; 74: 579-86.

34. Hewison M, Freeman L, Hughes SV, et al. Differential regulation of vitamin $\mathrm{D}$ receptor and its ligand in human monocyte-derived dendritic cells. J Immunol 2003; 170: 5382-90.

35. Gorman S, Kuritzky LA, Judge MA, et al. Topically applied 1,25-dihydroxyvitamin D3 enhances the suppressive activity of CD4+CD25+ cells in the draining lymph nodes. J Immunol 2007; 179: 6273-83.

36. Gregori S, Giarratana N, Smiroldo S, Uskokovic M, Adorini L. A 1alpha,25-dihydroxyvitamin D(3) analog enhances regulatory T-cells and arrests autoimmune diabetes in NOD mice. Diabetes 2002; 51: 1367-74.

37. Bousquet J, Schünemann HJ, Bousquet PJ, et al. How to design and evaluate randomized controlled trials in immunotherapy for allergic rhinitis: an ARIA-GA(2) LEN statement. Allergy 2011; 66: 765-74. 